\title{
Vasopressin Modulates Medial Prefrontal Cortex-Amygdala Circuitry during Emotion Processing in Humans
}

\author{
Caroline F. Zink, ${ }^{1}$ Jason L. Stein, ${ }^{1,3}$ Lucas Kempf, ${ }^{1}$ Shabnam Hakimi, ${ }^{1}$ and Andreas Meyer-Lindenberg ${ }^{1,2}$ \\ ${ }^{1}$ Genes, Cognition, and Psychosis Program, Naitonal Institute of Mental Health, National Institutes of Health, Department of Health and Human Services, \\ Bethesda, Maryland 20892, ${ }^{2}$ Central Institute of Mental Health, 68159 Mannheim, Germany, and ${ }^{3}$ Laboratory of NeuroImaging, Department of Neurology, \\ University of California, Los Angeles, Los Angeles, California 90095
}

The neuropeptide vasopressin is a modulator of mammalian social behavior and emotion, particularly fear, aggression, and anxiety. In humans, the neural circuitry underlying behavioral effects of vasopressin is unknown. Using a double-blind crossover administration of $40 \mathrm{IU}$ of vasopressin or placebo and functional MRI during processing of facial emotions in healthy male volunteers, we show that vasopressin specifically reduces differential activation in the subgenual cingulate cortex. Structural equation modeling of a previously evaluated circuit between amygdala, subgenual cingulate, and supragenual cingulate revealed altered effective connectivity between subgenual and supragenual cingulate under vasopressin. Our data demonstrate an impact of vasopressin on activity and connectivity in the cortical component of a medial prefrontal cortex-amygdala circuit implicated in emotional regulation, providing the first data on the neural basis for the effects of vasopressin on social behavior in humans with potential therapeutic significance for mood and anxiety disorders.

\section{Introduction}

Vasopressin is an evolutionarily highly conserved neuropeptide present in mammals, including humans. Vasopressin influences complex social behavior and emotional states, including, but not limited to, aggression, fear, and anxiety (Caldwell et al., 2008; Raggenbass, 2008; Viviani and Stoop, 2008), as demonstrated by studies on the effects of central vasopressin release (Engelmann et al., 2000), neural vasopressin receptor knockouts (Wersinger et al., 2002; Bielsky et al., 2004; Egashira et al., 2007), and pharmacological antagonism of neural vasopressin receptors (Griebel et al., 2002; Ferris et al., 2006; Bleickardt et al., 2009), which link vasopressin with the enhancement of fear, anxiety, and aggression. Human studies are scarce, but increasing brain vasopressin levels in men, via intranasal administration (Pietrowsky et al., 1996; Born et al., 2002), promotes aggressive behavioral responses to social stimuli (i.e., faces), as well as autonomic responsiveness to social threat and anxiety associated with angry facial expressions (Thompson et al., 2006), and enhances social stress in the Trier Social Stress Test (Ebstein et al., 2009). Also, human amygdala responses to negative social stimuli (i.e., fearful and

\footnotetext{
Received Sept. 30, 2009; revised March 25, 2010; accepted March 31, 2010.

This research was supported by the Intramural Research Program of the National Institute of Mental Health, National Institutes of Health. We thank Courtnea A. Rainey, Timothy 0. Laumann, and lan J. Lent for research assistance, Yunxia Tong and Qiang Chen for technical assistance, Gerald Overman and Judith Starling for pharmaceutical management, and Heike Tost for thoughtful discussion.

Correspondence should be addressed to either of the following: Dr. Caroline F. Zink National Institute of Mental Health, National Institutes of Health, 9000 Rockville Pike, Building 10, Room 3C101, Bethesda, Maryland 20814, E-mail: zinkc@mail.nih.gov; or Dr. Andreas Meyer-Lindenberg, Central Institute of Mental Health, Department of Psychiatry and Psychotherapy, University of Heidelberg/Medical Faculty Mannheim, J5, 68159 Mannheim, Germany, E-mail: a.meyer-lindenberg@zi-mannheim.de.

DOI:10.1523/JNEUROSCI.4899-09.2010

Copyright $\odot 2010$ the authors $\quad 0270-6474 / 10 / 307017-06 \$ 15.00 / 0$
}

angry facial expressions) are associated with genetic variations of the vasopressin V1a receptor (Meyer-Lindenberg et al., 2008).

The social/emotional effects of vasopressin (i.e., enhanced aggression, fear, and anxiety) are mediated centrally by vasopressin V1a (and possibly partially V1b) receptors (Raggenbass, 2008) present in lateral septum, hypothalamus, bed nucleus of the stria terminalis, hippocampus, amygdala, and brainstem (Loup et al., 1991; Young et al., 1999), and in monkey prefrontal cortex and cingulate cortex (Young et al., 1999). Of these structures, the amygdala is crucially involved in the processing of salient and emotional information, including (and of particularly relevance for the current study), but not limited to, playing a critical role in the expression and processing of fear/anxiety, the acquisition of conditioned fear, and the detection of threat (Davis and Whalen, 2001; Phan et al., 2004; LeDoux, 2007). Regulation of the amygdala fear response is central to maintaining appropriate emotional states and could contribute to anxiety disorders (Garner et al., 2009). A primary neural regulator of amygdala is medial prefrontal cortex (mPFC), which inhibits central amygdala (CeA) responses to basolateral amygdala input (Quirk et al., 2003), and two mPFC subregions, the subgenual cingulate cortex and supragenual cingulate cortex, are important for amygdala regulation (Hariri et al., 2003) and fear extinction (Phelps et al., 2004). A previously evaluated connectivity model of mPFC-amygdala circuitry in humans suggests directional influences from amygdala to subgenual cingulate to supragenual cingulate back to amygdala (Pezawas et al., 2005; Stein et al., 2007).

Together, these data suggest the hypothesis that vasopressin influences on fear and aggression may be mediated by the amygdala and its interactions with the mPFC; however, the neural effects of vasopressin administration in humans are unknown. Therefore, in the present study, we assessed the effects of vaso- 
pressin on $\mathrm{mPFC}$ and amygdala reactivity and connectivity using functional magnetic resonance imaging (fMRI) and a negative emotion-processing paradigm. This paradigm involves implicit encoding of social fear and anger and is known to engage mPFCamygdala circuitry, specifically increasing amygdala activity while decreasing activity in the subgenual and supragenual cingulate cortices (Hariri et al., 2002; Meyer-Lindenberg et al., 2006). We hypothesized that administration of vasopressin in human males would alter the fMRI signal in the amygdala and connectivity between amygdala, subgenual, and supragenual cingulate.

\section{Materials and Methods}

Participants. Twenty right-handed, Caucasian, healthy male volunteers aged $18-43$ years (mean age, 28.60 years; SD, 5.88 years) participated in the study. We limited the current investigation to male participants to avoid confounds related to known sexual dimorphic effects of vasopressin on emotional states (Bielsky et al., 2005; Thompson et al., 2006; de Vries, 2008). Volunteers were recruited from the Washington, D.C. metropolitan area and the National Institutes of Health community. Participants had no structural brain abnormalities, had no history of psychiatric or neurological disorders, and had normal electrocardiograms and blood pressure. Each participant gave written, informed consent for a protocol approved by the National Institute of Mental Health Institutional Review Board.

Experimental paradigm. Research volunteers participated in two fMRI sessions, 1 week apart, and self-administered either 40 IU of vasopressin or placebo intranasally under investigator supervision (double-blind) in each session. Intranasal administration of the vasopressin dosage (40 IU) produces significant accumulation of vasopressin in the CSF for up to $80 \mathrm{~min}$ in humans (Born et al., 2002). The drug order (vasopressin or placebo) was counterbalanced across subjects. The Pharmaceutical Development Section of the National Institutes of Health Pharmacy Department formulated the vasopressin and placebo solutions, and maintained the blind.

In both sessions, while in the scanner the participants performed a "face-matching task" (supplemental Fig. 1, available at www.jneurosci. org as supplemental material), a block-design, face-matching task involving implicit emotion processing known to robustly engage mPFCamygdala circuitry in humans (Hariri et al., 2002; Pezawas et al., 2005), as part of a neuroimaging task battery. The face-matching task is divided into eight blocks, four blocks of matching faces with fearful/angry facial expressions taken from the Ekman Pictures of Facial Affect stimulus set and four blocks of matching simple forms, i.e., circles and ellipses, as a sensorimotor control condition, alternatively. Each block contains six matching panels ( $5 \mathrm{~s}$ each), and for each panel, participants indicate which of the two bottom images, left or right, match the center top image, by pressing the left or right button, respectively, on a button pad using the right thumb. Instructions are displayed for $2 \mathrm{~s}$ at the beginning of each block: "Match Faces" or "Match Forms." The task began 56 min after drug/placebo administration to capture peak CSF vasopressin levels (Born et al., 2002) and lasted $4.6 \mathrm{~min}$.

Both before and after each of the scanning sessions, participants' current emotional states were assessed with the state versions of the StateTrait Anger Expression Inventory (Spielberger, 1988) and State-Trait Anxiety Inventory (Spielberger et al., 1983) to determine potential effects of vasopressin on current levels of anger and anxiety, respectively. Participants' subjective affective states of pleasure, arousal, and dominance were also assessed before and after the scanning sessions using the selfassessment manikin (Bradley and Lang, 1994). Potential drug effects on each rating questionnaire, as well as on task performance, were statistically determined using paired $t$ tests.

fMRI. Scanning was performed on a 3 tesla GE Signa scanner. During the face-matching task, for each participant 138 whole-brain scans were acquired to measure the T2-weighted blood oxygenation leveldependent (BOLD) effect with the following parameters: gradient-recall echo-planar imaging; repetition time, $2000 \mathrm{~ms}$; echo time, $30 \mathrm{~ms}$; flip angle, $90^{\circ}$; $64 \times 64$ matrix; field of view, $240 \mathrm{~mm}$; $283.5 \mathrm{~mm}$ slices acquired with an interleaved order of slice acquisition. Five additional scans were acquired at the beginning of a run to allow for steady-state magnetization (discarded from analysis). Head movement during scanning was minimized with a vacuum pillow and additional padding.

fMRI analysis. The fMRI data from both scanning sessions (vasopressin and placebo) were preprocessed and analyzed using Statistical Parametric Mapping (SPM5; http://www.fil.ion.ucl.ac.uk/spm/) (Friston et al., 1994). Motion correction to the first functional scan was performed using a six-parameter, rigid-body transformation. For each individual, the mean of the functional images was spatially normalized to the Montreal Neurological Institute (MNI) template conforming to the Talairach orientation system (Talairach and Tournoux, 1988) by applying a 12-parameter affine transformation followed by nonlinear warping (Ashburner and Friston, 1999). The computed transformation parameters were applied to all of the functional images, interpolated to a final voxel size of $3 \times 3 \times 3 \mathrm{~mm}^{3}$. Images were subsequently spatially smoothed with an $8 \mathrm{~mm}$ Gaussian kernel.

A random-effects, epoch-related statistical analysis was performed in a two-level procedure. At the first level, a separate general linear model was specified for each participant for each session. A set of boxcar functions, modeling the duration of each face-matching block separately, was convolved with a synthetic hemodynamic response function. The data were high-pass filtered (128 s cutoff) to remove low-frequency drifts, and serial correlations were accounted for by an autoregressive model of the first order. Contrast images were calculated for each participant in both sessions to compare brain activity during matching of fearful/angry faces and matching forms. Only data from the first half of the face-matching task were used in the analysis to avoid known neural habituation effects (Hariri et al., 2002) (see Results for habituation effects in the current study). The individual contrast images were then entered into a secondlevel random-effects region of interest (ROI) analysis to assess the group effect of vasopressin on activity in the mPFC (BA 25/32, which includes subgenual and supragenual cingulate) and amygdala. The ROI (supplemental Fig. 2, available at www.jneurosci.org as supplemental material), was defined a priori anatomically using the Brodmann Atlas in the WFU PickAtlas software (Maldjian et al., 2003). A one-sample $t$ test was used to investigate the resulting statistical maps for the contrasts in the vasopres$\sin$ and placebo groups separately. Subsequently, a paired $t$ test was used to statistically assess drug effects (vasopressin versus placebo) on resulting neural activity. The summary statistical maps were thresholded at $p<$ 0.05 , false discovery rate (FDR) corrected for multiple comparisons at the voxel level (Genovese et al., 2002) within the mPFC/amygdala ROI (voxel extent $=10$ ). While voxelwise FDR correction is a commonly implemented procedure in neuroimaging data analysis, it should be noted that Chumbley and colleagues (Chumbley and Friston, 2009; Chumbley et al., 2010) have recently argued that topological FDR control is superior, which, if replicated and adopted by the field, would question the rigor of voxelwise FDR correction, possibly requiring reconsideration of the results.

Effective connectivity analysis. Structural equation modeling (SEM) (McIntosh et al., 1994; Loehlin, 2003) of a circuit between the regions of interest, amygdala to subgenual cingulate to supragenual cingulate back to amygdala (Stein et al., 2007), was used to examine the effects of vasopressin on the network effective connectivity. Using SEM, significance of an overall network model, as well as the strength, direction, and significance of internode path coefficients, can be estimated between two conditions (Buckholtz and Meyer-Lindenberg, 2008). First, masks of the left and right amygdala (separately), subgenual cingulate, and supragenual cingulate were created as $10 \mathrm{~mm}$ spheres centered at the peak signal change in the ROIs (see Results concerning increases for amygdala, and decreases for subgenual and supragenual cingulate) during face matching under placebo. Task mean effects were removed to minimize the impact of coactivation on connectivity measures, which gave a "residual activity" time series. The median value of all voxels in each of the ROIs was extracted for each point in the "residual" fMRI time series. For each ROI, principal component analysis (PCA) was then used to determine consistent patterns of BOLD responses across subjects (Bullmore et al., 2000). The sign of each component, which is ambiguous in PCA, was based on the sign of the majority of points (http://www.models.life.ku. $\mathrm{dk} /$ source/signflipsvd/index.asp). The corrected first components of 
A

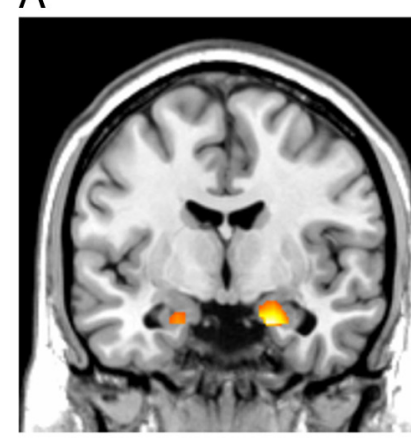

B

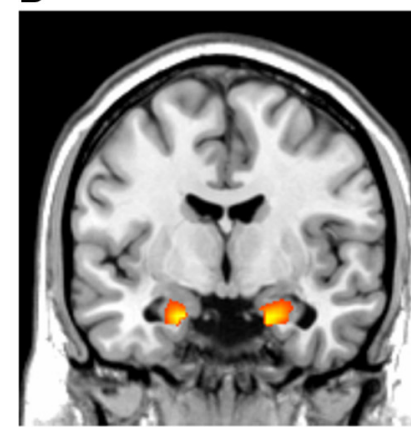

PLACEBO

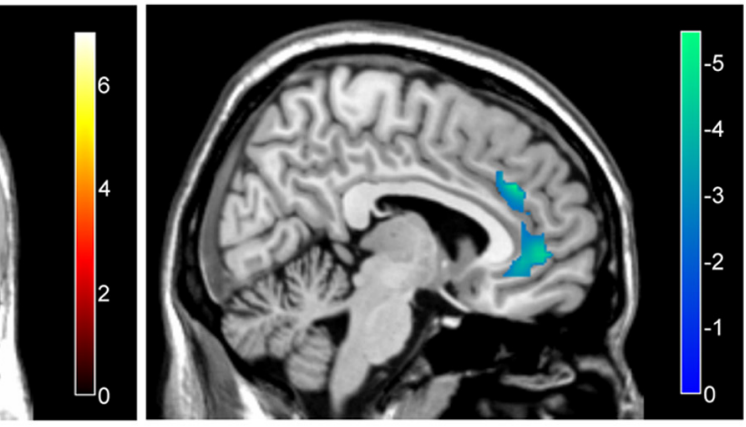

VASOPRESSIN
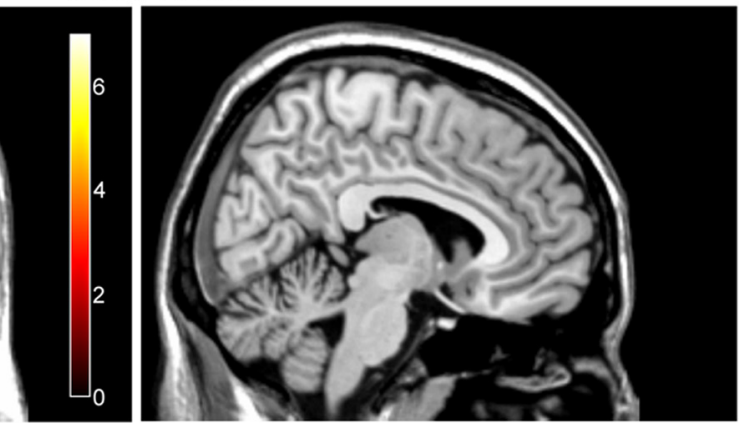

Figure 1. $A, B$, Significant changes in the amygdala and $\mathrm{mPFC} B O L D$ responses during face-matching blocks relative to formmatching blocks after administration of placebo $(\boldsymbol{A})$ and vasopressin $(\boldsymbol{B})$. In both the placebo and vasopressin conditions, bilateral amygdala activity was significantly increased during face matching (left panels; activation maps overlaid on coronal sections of a structural template MRI, $y=-6$ ). mPFC (subgenual and supragenual cingulate cortices) activity was significantly decreased during face matching after placebo but not after vasopressin administration (right panels; activation maps overlaid on sagittal sections of a structural template MRI, $x=6$ ). Colorbars represent $t$ values. Statistical significance was thresholded at $p<0.05$, corrected for multiple comparisons within the amygdala-mPFC regions of interest.

each region, which represent the most similar BOLD time course across subjects, were correlated with each other to form $3 \times 3$ correlation matrices for model fitting.

A validated model specifying paths from amygdala to subgenual cingulate, subgenual cingulate to supragenual cingulate, and supragenual cingulate back to amygdala (Paus, 2001; Ghashghaei and Barbas, 2002; Phillips et al., 2003; Pezawas et al., 2005; Stein et al., 2007) was fit to the observed data separately for the left and right hemispheres in the vasopressin and placebo conditions. Path coefficients were estimated by minimizing a maximum likelihood discrepancy function implemented in Matlab (Mathworks) using an annealing minimization program (Ingber, 1989). The value of the maximum likelihood discrepancy function multiplied by the degrees of freedom minus one gave a $\chi^{2}$ statistic that was used to accept or reject the null hypothesis of no difference between the observed and predicted covariance matrices in the model for each condition (i.e., vasopressin and placebo, separately). This $\chi^{2}$ statistic value was used to determine whether the model gives a plausible fit to the observed data. It should be noted, however, that a plausible fit is not mandatory for interpretation of effective connectivity differences between models (Protzner and McIntosh, 2006). In addition, because the fit of the model is dependent on both the effective degrees of freedom, which is a function of the number of scans acquired, and the number of path coefficients included in the model, the $\chi^{2}$ statistic may spuriously reject or accept the null hypothesis of model fit to the data (Bullmore et al., 2000). The overall difference in the fit of the model between the vasopressin and placebo conditions was assessed through a stacked models approach by fitting the observed data to (1) a case where each of the path coefficients between the two conditions are set to be equal, and (2) a case where all path coefficients are allowed to vary freely. If the difference between the case $1 \chi^{2}$ statistic and the case $2 \chi^{2}$ statistic is significant for a $\chi^{2}$ distribution with degrees of freedom equal to the total number of path coefficients in one model, then these two conditions have a signifi- cantly different fit of the observed data to the model. The difference between a particular path coefficient in two conditions is assessed through a stacked model approach by fitting (3) a case where a particular path coefficient is constrained to be the same in both conditions and (2) a case where all path coefficients are allowed to vary freely. If the difference between the case $3 \chi^{2}$ statistic and the case $2 \chi^{2}$ statistic is significant on a $\chi^{2}$ distribution with $1 \mathrm{df}$, then one can conclude that this path is significantly different between the two conditions.

\section{Results}

\section{Behavioral measures}

The task performance data are given in supplemental Table 1 (available at www. jneurosci.org as supplemental material). Participants performed the face-matching task with near perfect accuracy, and there was no significant effect of drug ( $p=$ $0.897, t=0.131)$. Participants responded significantly slower during face matching compared with control blocks in both the drug and placebo conditions (placebo: $p<0.001, t=4.485$; vasopressin: $p<$ $0.001 ; t=5.524)$. There was no effect of drug on reaction times overall ( $p=0.773$, $t=0.293)$, during face matching ( $p=$ $0.819, t=0.232$ ), or during form matching $(p=0.195, t=1.346)$.

Behavioral data from the prescan and postscan emotional state rating scales are given in supplemental Table 2 (available at www.jneurosci.org as supplemental material). The level of experienced arousal in both conditions (vasopressin and placebo) was significantly greater postscan compared with prescan (placebo: $p=0.024, t=2.445$; vasopressin: $p=0.030, t=2.349$ ). No other emotional measures (valence, dominance, anger, and anxiety levels) differed significantly between before and after scanning in either condition $(p>0.10)$. Vasopressin had no significant effect on any behavioral measurements of valence, arousal, dominance, anger, or anxiety ratings ( $p>$ $0.10)$.

\section{fMRI BOLD responses}

Consistent with previous studies (Hariri et al., 2002; MeyerLindenberg et al., 2006), under placebo matching fearful/angry faces compared with matching forms elicited a relative increase in amygdala activity and a relative decrease in mPFC activity, specifically in subgenual and supragenual cingulate cortices (Fig. $1 A$, Table 1). After vasopressin administration, matching fearful/angry faces compared with matching forms also evoked an increase in BOLD signal in the amygdala, but no differential response in mPFC (Fig. 1B, Table 1). Statistical comparison confirmed that the elicited activity in the amygdala was not significantly affected by vasopressin compared with placebo but that vasopressin administration abolished the decrease in $\mathrm{mPFC}$ activity specifically in the subgenual cingulate (Fig. 2, Table 1).

\section{Habituation effects}

As demonstrated previously in the face-matching task (Hariri et al., 2002), in the current study we observed habituation of neural responses during implicit negative emotion processing in the 
Table 1. Significant BOLD signal changes during face matching compared to forms matching after placebo or vasopressin administration

\begin{tabular}{|c|c|c|c|c|c|c|}
\hline \multirow[b]{2}{*}{ Brain region } & \multirow[b]{2}{*}{ Contrast direction } & \multicolumn{3}{|c|}{ Peak MNI coordinates } & \multirow[b]{2}{*}{ Voxels in cluster } & \multirow[b]{2}{*}{ Peak $t$ value } \\
\hline & & $x$ & $y$ & $z$ & & \\
\hline \multicolumn{7}{|l|}{ Placebo } \\
\hline Right amygdala & Faces $>$ Forms & 18 & -6 & -24 & 37 & 6.91 \\
\hline Left amygdala & Faces $>$ Forms & -21 & -6 & -24 & 14 & 4.16 \\
\hline Supragenual cingulate & Forms $>$ Faces & 6 & 36 & 30 & 335 & 5.27 \\
\hline Including subgenual cingulate & Forms $>$ Faces & -6 & 39 & -9 & & 4.37 \\
\hline \multicolumn{7}{|l|}{ Vasopressin } \\
\hline Left amygdala & Faces $>$ Forms & -18 & -6 & -24 & 34 & 5.55 \\
\hline Right amygdala & Faces $>$ Forms & 21 & -6 & -24 & 50 & 5.29 \\
\hline \multicolumn{7}{|l|}{ Vasopressin > Placebo } \\
\hline Subgenual cingulate & Faces $>$ Forms & 3 & 39 & -9 & 25 & 4.50 \\
\hline $\begin{array}{l}\text { Placebo }>\text { Vasopressin } \\
\quad \text { No significant activations }\end{array}$ & & & & & & \\
\hline
\end{tabular}

Significance was measured at $p<0.05$, FDR-corrected for multiple comparisons within the mPFC-amygdala region of interest.

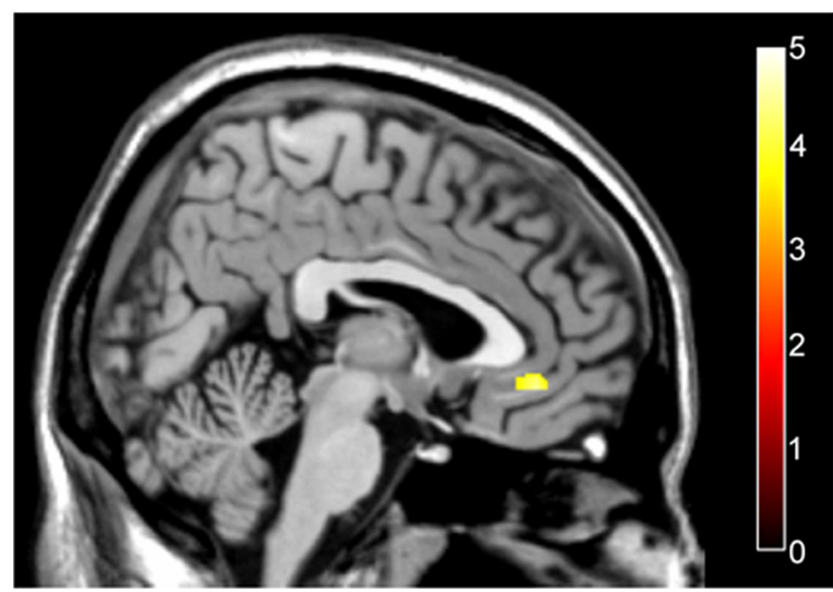

Figure 2. Significantly greater subgenual cingulate cortex activation after vasopressin administration compared with placebo during face-matching blocks relative to form-matching blocks. The activation map of the subgenual cingulate is overlaid on a sagittal section of a structural template MRI $(x=3)$. The colorbar represents $t$ values.

face-matching blocks, in support of subjecting only the first two face-matching blocks to the statistical analysis described above. Under placebo, neural responses elicited by the first two facematching blocks relative to the control condition-increases in amygdala activity and decreases in MPFC activity-were significantly diminished in the second two face-matching blocks. Specifically, a statistical comparison between the fMRI signal evoked during the face-matching blocks in the first half of the task compared with the second half revealed significantly greater signal changes in the amygdala and mPFC (subgenual cingulate) during the first half of the task (first half $>$ second half: faces $>$ forms: 24 , $0,-24 ; t=3.94$ and forms $>$ faces: $3,39,-9 ; t=2.81$ ). Furthermore, the effect of intranasal administration of vasopressin on neural activity during face-matching blocks was also susceptible to habituation; under vasopressin relative to placebo, subgenual cingulate activity was greater during the first two face-matching blocks compared with the second two face-matching blocks (first half $>$ second half: $3,24,-12 ; t=4.76)$.

\section{Effective connectivity}

A $\chi^{2}$ test was unable to reject the null hypothesis of no difference between observed and predicted covariance matrices, thus demonstrating that the previously validated model, amygdala to subgenual cingulate to supragenual cingulate to amygdala (Pezawas et al., 2005; Stein et al., 2007), provided a plausible fit to the data from the current study bilaterally under both placebo (left, $p=$ 0.093; right, $p=0.162$ ) and vasopressin (left, $p=0.152$; right $p=0.122$ ). Vasopressin administration elicited a significant alteration of functional interactions in this circuit in both the left ( $p=0.003)$ and right $(p=0.001)$ hemispheres. This difference was largely due to the highly significant difference between the path coefficients for the connection from subgenual to supragenual cingulate after vasopressin administration compared with placebo (left, $p=0.0003$; right, $p=0.0004$ ). Specifically, the influence of subgenual cingulate on supragenual cingulate was positive under placebo (path coefficients: left, 0.31; right, 0.30 ) and negative under vasopressin (path coefficients: left, -0.12 ; right, -0.12) (supplemental Fig. 3, available at www.jneurosci. org as supplemental material). The path coefficients for the connections from amygdala to subgenual cingulate and from supragenual cingulate to amygdala were not statistically different between vasopressin and placebo (left amygdala to subgenual, $p=0.548$; right amygdala to subgenual, $p=0.671$; supragenual to left amygdala, $p=0.408$; supragenual to right amygdala, $p=$ 0.125).

\section{Discussion}

Using fMRI and a negative emotion-matching task known to engage amygdala-prefrontal cortex circuitry (Hariri et al., 2002), we provide the first neuroimaging data on the effect of acute vasopressin administration in human brain. Vasopressin abolished the fear-related decrease in subgenual cingulate activity and altered the connectivity between subgenual and supragenual cingulate. These results are indicative of a neural effect of vasopressin within the brain's fear regulatory system.

Activity within the amygdala is tightly regulated by the $\mathrm{mPFC}$ (Quirk et al., 2003). A validated model of mPFC-amygdala connectivity, amydala to subgenual cingulate to supragenual cingulate to amygdala, has been established as a regulatory negative feedback loop (Pezawas et al., 2005; Stein et al., 2007). Our current findings are consistent with this model. Potentially by acting directly on vasopressin receptors within the subgenual cingulate (Young et al., 1999), vasopressin abolished the activity decrease normally present during fear processing. Furthermore, vasopressin significantly altered the connectivity; whereas, under placebo an increase in subgenual cingulate activity predicted an increase in supragenual cingulate activity (Stein et al., 2007), after vasopressin administration, the sign of the interaction between these cortical areas reversed, providing a mechanism by which vasopressin may alter emotional behavior. Although functional interpretation of effective connectivity is cautionary, if the negative 
interaction between subgenual and supragenual cingulate reflects functional inhibition, this would predict a reduction of negative feedback to amygdala through $\mathrm{mPFC}$ regulation, leading to more sustained activity to threatening social stimuli, in good agreement with the behavioral effects of vasopressin.

Contrary to our hypothesis, no direct vasopressin effects on amygdala activation were found, despite the study being well powered to observe even moderate changes in amygdala activity with the methods used (Hariri et al., 2002; Drabant et al., 2006; Meyer-Lindenberg et al., 2008), including previously under oxytocin administration (Kirsch et al., 2005). This may imply that, in humans, acute vasopressin is not acting directly in the amygdala to influence emotional behavior, but rather indirectly via the regulatory feedback loop involving the mPFC, as discussed above, at least using the task conditions used here. However, while somewhat speculative, it is important to point out that our data do not necessary rule out a direct effect of vasopressin in the amygdala because it is generally accepted that the fMRI BOLD signal is more strongly related to synaptic input rather than to the rate of action potentials (Logothetis et al., 2001). As a target of amygdala efferents, the relatively increased signal in the subgenual cingulate during fear/angry face matching in the vasopressin condition compared with placebo may signify greater task-related amygdala input to this region, which is then not properly regulated due to the vasopressin-driven interference of subgenual cingulatesupragenual cingulate connectivity in the negative feedback loop to amygdala. In support of this speculation, rather than directly inhibiting the medial CeA, the main output region of the amygdala (Likhtik et al., 2005), the mPFC decreases amygdala output via projections to the lateral $\mathrm{CeA}$, which in turn inhibits the medial CeA via GABAergic interneurons (Viviani and Stoop, 2008). Vasopressin receptors are expressed in the medial CeA, as opposed to the lateral CeA receiving the $\mathrm{MPFC}$ input, and activation of these vasopressin receptors evokes an increase in medial CeA output firing (Viviani and Stoop, 2008). Interestingly, an investigation of vasopressin V1a receptor genetic variation using the current paradigm did reveal amygdala activation differences (Meyer-Lindenberg et al., 2008), suggesting potential neural differences between chronic and acute (as in the current study) changes in vasopressin neurotransmission, as demonstrated in a previous behavior study (Bruins et al., 1995). Whether the effects of vasopressin on $\mathrm{mPFC}$-amygdala circuitry found in the current investigation resulted from direct activation of vasopressin receptors in the amygdala or direct activation of vasopressin receptors in the subgenual cingulate (or both) remains to be studied further in humans. It should be noted that the current study focuses solely on the potential neural correlates of the aggression/ fear-related effects of vasopressin. Other behavioral effects of vasopressin [e.g., those related to pair-bonding, social recognition, and memory (Caldwell et al., 2008)] may involve other neural circuitry to be revealed in future studies.

In the present study, acute vasopressin did not have an effect on any behavioral measures assessed, including anxiety, anger, and arousal ratings. Similarly, a previous study using the same paradigm and intranasal application of the neuropeptide oxytocin also did not find any effect on anxiety or arousal levels (Kirsch et al., 2005). As with that study, our data indicate the sensitive nature of fMRI to detect neural effects of vasopressin during emotion processing, more so than behavioral ratings. In contrast, a previous behavioral study found that intranasal administration of vasopressin in humans increased state anxiety and increased skin conductance responses, a measure of arousal, to angry faces (Thompson et al., 2006). The resulting behavioral differences between these studies are likely due to task differences; in the present study, the emotion on the faces was implicitly processed, whereas in the previous study participants were explicitly making inferences based on the emotions presented. It should be noted that our participants were unable to reliably distinguish vasopressin from placebo.

Because only healthy males participated in the study, we cannot rule out the possibility that our findings are sex specific. Several pieces of evidence in both the animal and human literature suggest that some effects of vasopressin on emotional states are sexually dimorphic (Bielsky et al., 2005; Thompson et al., 2006; de Vries, 2008), making it important to investigate the effects of vasopressin on neural circuitry during emotion processing in human females as well. It should also be noted that the FDR correction for multiple comparisons, as implemented in the current study, allows 5\% false-positive voxels per tested contrast; therefore, the results may require replication.

In conclusion, to our knowledge this is the first neuroimaging study of the effects of vasopressin on social emotion-related neural responses in humans. The data show that vasopressin influences activity within the mPFC-amygdala circuitry, specifically modulating subgenual cingulate cortex activity and connectivity patterns. These results provide a potential neural basis for the influence of vasopressin on social behavior, particularly related to fear and anxiety, by suggesting that vasopressin interferes with a negative feedback loop involving amygdala, subgenual, and supragenual cingulate. Since analogs of vasopressin show therapeutic potential (Griebel et al., 2002), our findings have potential clinical significance for psychiatric disorders with social emotional dysfunction, including autism, anxiety disorders, and schizophrenia.

\section{References}

Ashburner J, Friston KJ (1999) Nonlinear spatial normalization using basis functions. Hum Brain Mapp 7:254-266.

Bielsky IF, Hu SB, Szegda KL, Westphal H, Young LJ (2004) Profound impairment in social recognition and reduction in anxiety-like behavior in vasopressin V1a receptor knockout mice. Neuropsychopharmacology 29:483-493.

Bielsky IF, Hu SB, Young LJ (2005) Sexual dimorphism in the vasopressin system: lack of an altered behavioral phenotype in female V1a receptor knockout mice. Behav Brain Res 164:132-136.

Bleickardt CJ, Mullins DE, Macsweeney CP, Werner BJ, Pond AJ, Guzzi MF, Martin FD, Varty GB, Hodgson RA (2009) Characterization of the V1a antagonist, JNJ-17308616, in rodent models of anxiety-like behavior. Psychopharmacology (Berl) 202:711-718.

Born J, Lange T, Kern W, McGregor GP, Bickel U, Fehm HL (2002) Sniffing neuropeptides: a transnasal approach to the human brain. Nat Neurosci 5:514-516.

Bradley MM, Lang PJ (1994) Measuring emotion: the Self-Assessment Manikin and the Semantic Differential. J Behav Ther Exp Psychiatry 25:49-59.

Bruins J, Hijman R, Van Ree JM (1995) Effect of acute and chronic treatment with desglycinamide-[Arg8] vasopressin in young male and female volunteers. Peptides 16:179-186.

Buckholtz JW, Meyer-Lindenberg A (2008) MAOA and the neurogenetic architecture of human aggression. Trends Neurosci 31:120-129.

Bullmore E, Horwitz B, Honey G, Brammer M, Williams S, Sharma T (2000) How good is good enough in path analysis of fMRI data? Neuroimage 11:289-301.

Caldwell HK, Lee HJ, Macbeth AH, Young WS 3rd (2008) Vasopressin: behavioral roles of an "original" neuropeptide. Prog Neurobiol 84:1-24.

Chumbley JR, Friston KJ (2009) False discovery rate revisited: FDR and topological inference using Gaussian random fields. Neuroimage 44:62-70.

Chumbley J, Worsley K, Flandin G, Friston K (2010) Topological FDR for neuroimaging. Neuroimage 49:3057-3064.

Davis M, Whalen PJ (2001) The amygdala: vigilance and emotion. Mol Psychiatry 6:13-34. 
de Vries GJ (2008) Sex differences in vasopressin and oxytocin innervation of the brain. Prog Brain Res 170:17-27.

Drabant EM, Hariri AR, Meyer-Lindenberg A, Munoz KE, Mattay VS, Kolachana BS, Egan MF, Weinberger DR (2006) Catechol O-methyltransferase val158met genotype and neural mechanisms related to affective arousal and regulation. Arch Gen Psychiatry 63:1396-1406.

Ebstein RP, Israel S, Lerer E, Uzefovsky F, Shalev I, Gritsenko I, Riebold M, Salomon S, Yirmiya N (2009) Arginine vasopressin and oxytocin modulate human social behavior. Ann N Y Acad Sci 1167:87-102.

Egashira N, Tanoue A, Matsuda T, Koushi E, Harada S, Takano Y, Tsujimoto G, Mishima K, Iwasaki K, Fujiwara M (2007) Impaired social interaction and reduced anxiety-related behavior in vasopressin V1a receptor knockout mice. Behav Brain Res 178:123-127.

Engelmann M, Wotjak CT, Ebner K, Landgraf R (2000) Behavioural impact of intraseptally released vasopressin and oxytocin in rats. Exp Physiol 85:125S-130S.

Ferris CF, Lu SF, Messenger T, Guillon CD, Heindel N, Miller M, Koppel G, Robert Bruns F, Simon NG (2006) Orally active vasopressin V1a receptor antagonist, SRX251, selectively blocks aggressive behavior. Pharmacol Biochem Behav 83:169-174.

Friston KJ, Holmes AP, Worsley KJ, Poline J-P, Frith CD, Frackowiak RSJ (1994) Statistical parametric maps in functional imaging: a general linear approach. Hum Brain Mapp 2:189-210.

Garner M, Möhler H, Stein DJ, Mueggler T, Baldwin DS (2009) Research in anxiety disorders: from the bench to the bedside. Eur Neuropsychopharmacol 19:381-390.

Genovese CR, Lazar NA, Nichols T (2002) Thresholding of statistical maps in functional neuroimaging using the false discovery rate. Neuroimage 15:870-878.

Ghashghaei HT, Barbas H (2002) Pathways for emotion: interactions of prefrontal and anterior temporal pathways in the amygdala of the rhesus monkey. Neuroscience 115:1261-1279.

Griebel G, Simiand J, Serradeil-Le Gal C, Wagnon J, Pascal M, Scatton B, Maffrand JP, Soubrie P (2002) Anxiolytic- and antidepressant-like effects of the non-peptide vasopressin V1b receptor antagonist, SSR149415, suggest an innovative approach for the treatment of stress-related disorders. Proc Natl Acad Sci U S A 99:6370-6375.

Hariri AR, Tessitore A, Mattay VS, Fera F, Weinberger DR (2002) The amygdala response to emotional stimuli: a comparison of faces and scenes. Neuroimage 17:317-323.

Hariri AR, Mattay VS, Tessitore A, Fera F, Weinberger DR (2003) Neocortical modulation of the amygdala response to fearful stimuli. Biol Psychiatry 53:494-501.

Ingber L (1989) Very fast simulated re-annealing. Math Comput Model 12:967-973.

Kirsch P, Esslinger C, Chen Q, Mier D, Lis S, Siddhanti S, Gruppe H, Mattay VS, Gallhofer B, Meyer-Lindenberg A (2005) Oxytocin modulates neural circuitry for social cognition and fear in humans. J Neurosci 25:11489-11493.

LeDoux J (2007) The amygdala. Curr Biol 17:R868-R874.

Likhtik E, Pelletier JG, Paz R, Paré D (2005) Prefrontal control of the amygdala. J Neurosci 25:7429-7437.

Loehlin JC (2003) Latent variable models: an introduction to factor, path, and structural equation analysis, Ed 4. London: Psychology Press.

Logothetis NK, Pauls J, Augath M, Trinath T, Oeltermann A (2001) Neurophysiological investigation of the basis of the fMRI signal. Nature 412:150-157.

Loup F, Tribollet E, Dubois-Dauphin M, Dreifuss JJ (1991) Localization of high-affinity binding sites for oxytocin and vasopressin in the human brain. An autoradiographic study. Brain Res 555:220-232.

Maldjian JA, Laurienti PJ, Kraft RA, Burdette JH (2003) An automated method for neuroanatomic and cytoarchitectonic atlas-based interrogation of fMRI data sets. Neuroimage 19:1233-1239.

McIntosh AR, Grady CL, Ungerleider LG, Haxby JV, Rapoport SI, Horwitz B (1994) Network analysis of cortical visual pathways mapped with PET. J Neurosci 14:655-666.

Meyer-Lindenberg A, Buckholtz JW, Kolachana B, Hariri AR, Pezawas L, Blasi G, Wabnitz A, Honea R, Verchinski B, Callicott JH, Egan M, Mattay V, Weinberger DR (2006) Neural mechanisms of genetic risk for impulsivity and violence in humans. Proc Natl Acad Sci U S A 103:6269-6274.

Meyer-Lindenberg A, Kolachana B, Gold B, Olsh A, Nicodemus KK, Mattay V, Dean M, Weinberger DR (2009) Genetic variants in AVPR1A linked to autism predict amygdala activation and personality traits in healthy humans. Mol Psychiatry 14:968-975.

Paus T (2001) Primate anterior cingulate cortex: where motor control, drive and cognition interface. Nat Rev Neurosci 2:417-424.

Pezawas L, Meyer-Lindenberg A, Drabant EM, Verchinski BA, Munoz KE, Kolachana BS, Egan MF, Mattay VS, Hariri AR, Weinberger DR (2005) 5-HTTLPR polymorphism impacts human cingulate-amygdala interactions: a genetic susceptibility mechanism for depression. Nat Neurosci 8:828-834.

Phan KL, Wager TD, Taylor SF, Liberzon I (2004) Functional neuroimaging studies of human emotions. CNS Spectr 9:258-266.

Phelps EA, Delgado MR, Nearing KI, LeDoux JE (2004) Extinction learning in humans: role of the amygdala and vmPFC. Neuron 43:897-905.

Phillips ML, Drevets WC, Rauch SL, Lane R (2003) Neurobiology of emotion perception I: the neural basis of normal emotion perception. Biol Psychiatry 54:504-514.

Pietrowsky R, Strüben C, Mölle M, Fehm HL, Born J (1996) Brain potential changes after intranasal vs. intravenous administration of vasopressin: evidence for a direct nose-brain pathway for peptide effects in humans. Biol Psychiatry 39:332-340.

Protzner AB, McIntosh AR (2006) Testing effective connectivity changes with structural equation modeling: what does a bad model tell us? Hum Brain Mapp 27:935-947.

Quirk GJ, Likhtik E, Pelletier JG, Paré D (2003) Stimulation of medial prefrontal cortex decreases the responsiveness of central amygdala output neurons. J Neurosci 23:8800-8807.

Raggenbass M (2008) Overview of cellular electrophysiological actions of vasopressin. Eur J Pharmacol 583:243-254.

Spielberger CD (1988) Manual for the state-trait anger expression inventory (STAXI). Odessa, FL: Psychological Assessment Resources.

Spielberger CD, Gorsuch RL, Lushene PR, Vagg PR, Jacobs AG (1983) Manual for the state-trait anxiety inventory (form Y). Palo Alto, CA: Consulting Psychologists Press.

Stein JL, Wiedholz LM, Bassett DS, Weinberger DR, Zink CF, Mattay VS, Meyer-Lindenberg A (2007) A validated network of effective amygdala connectivity. Neuroimage 36:736-745.

Talairach J, Tournoux P (1988) Co-planar stereotaxic atlas of the human brain: 3-dimensional proportional system: an approach to cerebral imaging. New York: Thieme Medical Publishers.

Thompson RR, George K, Walton JC, Orr SP, Benson J (2006) Sex-specific influences of vasopressin on human social communication. Proc Natl Acad Sci U S A 103:7889-7894.

Viviani D, Stoop R (2008) Opposite effects of oxytocin and vasopressin on the emotional expression of the fear response. Prog Brain Res 170:207218.

Wersinger SR, Ginns EI, O’Carroll AM, Lolait SJ, Young WS 3rd (2002) Vasopressin $\mathrm{V} 1 \mathrm{~b}$ receptor knockout reduces aggressive behavior in male mice. Mol Psychiatry 7:975-984.

Young LJ, Toloczko D, Insel TR (1999) Localization of vasopressin (V1a) receptor binding and mRNA in the rhesus monkey brain. J Neuroendocrinol 11:291-297. 